\title{
Study on cyclic crosslinked polyphosphazene microspheres and its adsorption behavior for uranium (VI)
}

\author{
Meixue $\mathrm{Xu}^{1,{ }^{*}}, \mathrm{Kaifa}_{\mathrm{Liao}}{ }^{1}$, Mouwu $\mathrm{Liu}^{1}$,Yi Tan ${ }^{1}$,Yanfei Wang ${ }^{1}$ \\ ${ }^{1}$ School of chemistry and chemical engineering, University of South China , 421000, PRC
}

\begin{abstract}
Poly (cyclotriphosphazene-co-4,4 '- diaminodiphenylsulfone) (PZD) microspheres were synthesi zed by precipitation polymerization of Hexachlorocyclotriphosphazene (HCCP) and polyfunctional organic monomers. The products were characterized by FTIR, SEM-EDS, XPS and bet. The adsorption behavior of PZD microspheres for uranium (VI) in aqueous solution and the influence of adsorption behavior were disc ussed. The results show that the PZD microspheres have a certain adsorption capacity for uranium (VI) in a queous solution. When $\mathrm{pH}=3.5$, adsorption time is $6 \mathrm{~h}$, solid-liquid ratio is $2.0 \mathrm{~g} \cdot \mathrm{L}-1$ and initial concentra tion of uranium (VI) is $30 \mathrm{mg} \cdot \mathrm{L}-1$, the adsorption rate of uranium reaches the maximum.
\end{abstract}

\section{INTRODUCTION}

At present, many methods have been developed to remo ve uranium (VI) from aqueous solution. However, many traditional methods have their own limitations. For exam ple, although membrane separation technology can effect ively remove uranium, the cost of this method is too high [1]. Chemical precipitation method is easy to operate an $\mathrm{d}$ low cost, but it is easy to cause secondary pollution [2]. Compared with the above two methods, adsorption meth od is widely favored because of its easy implementation, low cost and few secondary pollutants. Hai Nguyen tran [3] synthesized a new adsorbent for uranium (VI) adsorp tion by impregnating br PADAP onto multi walled carbo n nanotubes (MWCNTs). Xiangke Wang [4] has synthes ized magnetic titanate nanosheets (Fe3O4@ TNS) to ad sorb uranium (VI) in wastewater, and the maximum adso rption capacity is relatively large. Ramzi zarrougui [5] us ed nonfluorinated ionic liquids (ILS) to extract uranium (VI) from radioactive wastewater. Polyphosphazenes are a kind of new polymer materials with unique $\mathrm{P}=\mathrm{n}$ struc tural units and active p-cl groups. Their physical and che mical properties can be adjusted by nucleophilic substitu tion of functional groups. A poly (cyclotriphosphazene $\mathrm{c}$ o-4,4 '- diaminodiphenylsulfone) microsphere (PZD) was synthesized by precipitation polymerization of Hexachlo rocyclotriphosphazene (HCCP) and 4,4-diaminodiphenyl sulfone (DDS) under the protection of nitrogen and trieth ylamine (tea). The microspheres were used to adsorb ura nium (VI) from radioactive waste water.

\section{Experimental methods}

\subsection{Experimental process}

\subsubsection{Preparation of $P Z D$ microspheres}

65g HCCP and 4,4-diaminodiphenylsulfone (DDS) were dissolved in $200 \mathrm{ml}$ acetonitrile, and then the mixed solut ion was poured into a three port flask. After the solid wa s completely dissolved, nitrogen was used as protective $\mathrm{g}$ as. The three port flask was placed in an ultrasonic instru ment $(200 \mathrm{~W}, 40 \mathrm{KHz})$ for ultrasonic reaction, and the rea ction temperature was set at $50{ }^{\circ} \mathrm{C}$. After 5 minutes of ult rasound, $3 \mathrm{ml}$ triethylamine was added dropwise into the three port flask. After ultrasonic treatment for 6 hours, th e reaction system was transferred to an oil bath, heated in an oil bath at $50{ }^{\circ} \mathrm{C}$ and stirred by magnetic force for 6 hours.

At the end of the reaction, the reaction product was centr ifuged in a centrifuge $(800 \mathrm{r} / \mathrm{min})$ for 5 minutes, the sup ernatant was removed, and the white precipitate was was hed several times with anhydrous ethanol and deionized water. Finally, the washed solid material was dried in a v acuum drying oven at $60{ }^{\circ} \mathrm{C}$ for 48 hours to obtain the sy nthetic product.

\subsubsection{Preparation of uranium (VI) standard solution}

$1 \mathrm{~g} \cdot \mathrm{L}-1$ of uranium (VI) reserve solution was prepare $\mathrm{d}$, and then the reserve solution was gradually diluted to $10 \mathrm{mg} \cdot \mathrm{L}-1,20 \mathrm{mg} \cdot \mathrm{L}-1,30 \mathrm{mg} \cdot \mathrm{L}-1,40 \mathrm{mg} \cdot \mathrm{L}-$ $1,50 \mathrm{mg} \cdot \mathrm{L}-1$ and $60 \mathrm{mg} \cdot \mathrm{L}-1$. Measure $1 \mathrm{ml}$ of the a bove solution respectively, add $1 \mathrm{ml}$ of arsenazo Tris, titr ate it with chloroacetic acid sodium acetate buffer solutio $\mathrm{n}$ with $\mathrm{pH}=2.5$ to the scale line, take deionized water as blank sample, measure it in parallel for three times on th $\mathrm{e}$ visible spectrophotometer, and obtain the correspondin $\mathrm{g}$ absorbance at each concentration, which is linearly fitt ed by origin [6]. The linear fitting equation obtained is th

\footnotetext{
* Corresponding author: xmx_2902088301@163.com
} 
e standard curve of uranium (VI) solution.

\subsubsection{Effect of $\mathrm{pH}$ value on adsorption of uranium (V) by PZD microspheres}

$10 \mathrm{ml}$ of $30 \mathrm{mg}$ - L-1 uranium (VI) solution was accura tely measured. The $\mathrm{pH}$ of the solution was adjusted to 2 , 3.0, 4.0, 5.0 and 6.0 with $\mathrm{HNO} 3$ and $\mathrm{NaOH}$ respectively. $20 \mathrm{mg}$ PZD microspheres were added respectively, and $\mathrm{t}$ he adsorption time was $6 \mathrm{~h}$ under the condition of oscilla tion rate of $120 \mathrm{rpm}$ and temperature of $25{ }^{\circ} \mathrm{C}$. After the oscillation, the reaction solution was separated by ultrafil tration membrane. $1 \mathrm{ml}$ of filtrate was transferred into a 10 $\mathrm{ml}$ volumetric flask, and then $1 \mathrm{ml}$ of arsenazo III $(0.05$ $\mathrm{wt} \%$ ) chromogenic agent was transferred into the vol umetric flask with a pipette gun, Then add chloroacetic a cid sodium acetate buffer solution with $\mathrm{pH}$ of 2.5 dropwi se to the scale line, and determine the absorbance of the $f$ iltrate by uv- 2100 spectrophotometer, so as to analyze the effect of $\mathrm{pH}$ on the adsorption of uranium (VI) by cycl ocrosslinked polyphosphazene phloretin nanospheres. $\mathrm{Ca}$ lculation formula of adsorption capacity (q) and removal rate [6] are as follows:

$$
\begin{aligned}
& \mathrm{Q}(\mathrm{mg} \mathrm{g} \cdot)=\frac{\left(\mathrm{C}_{0}-\mathrm{C}_{\mathrm{c}}\right) \mathrm{V}}{\mathrm{m}} \\
& \mathrm{R}(\%)=\left(\mathrm{C}_{0}-\underline{\left.\mathrm{C}_{\mathrm{o}}\right)}\right.
\end{aligned}
$$

Where, $\mathrm{q}$ is the adsorption capacity (mg $\bullet \mathrm{g}-1), \mathrm{C} 0$ and $\mathrm{CE}$ represent the concentration of uranium (VI) ion befor e and after adsorption ( $\mathrm{mg} \cdot \mathrm{L}-1), \mathrm{V}$ is the volume of ur anium (VI) solution (L), and $\mathrm{M}$ is the amount of adsorbe nt (g).

\subsubsection{The effect of solid-liquid ratio on adsorption of uranium (VIby PZD microspheres}

Accurately measure $10 \mathrm{ml}$ of $30 \mathrm{mg}$ - L-1 uranium (VI) solution and adjust the $\mathrm{pH}$ of the solution to $35.5 \mathrm{mg}, 10$ $\mathrm{mg}, 15 \mathrm{mg}, 20 \mathrm{mg}, 25 \mathrm{mg}$ and 30mg PZD microspheres $\mathrm{w}$ ere added respectively. Under the condition of oscillation rate of $120 \mathrm{rpm}$ and temperature of $25{ }^{\circ} \mathrm{C}$, the adsorption was vibrated for $6 \mathrm{~h}$. After the oscillation, the solid-liquid separation of the reaction solution was carried out by ult rafiltration membrane. $1 \mathrm{ml}$ of the filtrate was transferred into a $10 \mathrm{ml}$ volumetric flask, and then $1 \mathrm{ml}$ of arsenazo III $(0.05 \mathrm{wt} \%)$ chromogenic agent was transferred into th $\mathrm{e}$ volumetric flask by pipette gun. Then the $\mathrm{pH} 2.5$ chlor oacetic acid sodium acetate buffer solution was added $\mathrm{dr}$ opwise to the scale line with a rubber tipped burette, and the absorbance of the filtrate was determined by uv- 2100 spectrophotometer, so as to analyze the effect of solid-li quid ratio on the adsorption of uranium (VI) by cyclicall y crosslinked polyphosphazene phloretin nanospheres.

\subsubsection{Effect of initial concentration of uranium (VI) o $n$ adsorption of uranium (VI) by PZD microspheres}

The concentration of $10 \mathrm{mg} \cdot \mathrm{L}-1,20 \mathrm{mg} \cdot \mathrm{L}-1,30 \mathrm{~m}$ $\mathrm{g} \cdot \mathrm{L}-1,40 \mathrm{mg} \cdot \mathrm{L}-1$ and $50 \mathrm{mg} \cdot \mathrm{L}-1$ of uranium (V
I) solution was accurately measured. The $\mathrm{pH}$ of the soluti on was adjusted to 3.5 with $\mathrm{HNO} 3$ and $\mathrm{NaOH}$ respective ly. $20 \mathrm{mg}$ PZD microspheres were added. The shaking ra te was 120 RPM and the adsorption time was $6 \mathrm{~h}$ at $25^{\circ} \mathrm{C}$. After shaking, the reaction solution was separated b y ultrafiltration membrane. $1 \mathrm{ml}$ of filtrate was put into a $10 \mathrm{ml}$ volumetric flask, Then, $1 \mathrm{ml}$ arsenazo III $(0.05 \mathrm{w} t \%)$ chromogenic agent was transferred by pipette gun an d added into volumetric flask. Then, chloroacetic acid so dium acetate buffer solution with $\mathrm{pH}$ of 2.5 was added dr opwise with rubber tip dropper to make volume to the sc ale line. The absorbance of the filtrate was determined $b$ y uv-2100 spectrophotometer to analyze the effect of init ial concentration on the adsorption of uranium (VI) by P ZD.

\section{Results and discussion}

\subsection{Characterization of PZD microspheres}

\subsubsection{Infrared characterization of PZD microspheres}

The absorption peaks at $3361 \mathrm{~cm}-1$ and $3215 \mathrm{~cm}-1$ are $\mathrm{t}$ he stretching vibration peaks of - NH2. This indicates tha $t$ the polymerized PZD microspheres contain a certain a mount of - NH2 group. Obviously, the two strong absorp tion peaks of $1593 \mathrm{~cm}-1$ and $1500 \mathrm{~cm}-1$ are the absorptio $\mathrm{n}$ peaks of $\mathrm{C}=\mathrm{C}$ in aromatics. $1300 \mathrm{~cm}-1$ and $1103 \mathrm{~cm}-1$ are characteristic absorption peaks of $\mathrm{o}=\mathrm{s}=\mathrm{O}$ stretching vibration of sulfodiphenol group. The characteristic a bsorption peak of $\mathrm{P}=\mathrm{n}$ stretching vibration is at $1143 \mathrm{~cm}$ $-1.880 \mathrm{~cm}-1$ is the stretching vibration peak of $p-n$ and 9 $31 \mathrm{~cm}-1$ is the stretching vibration peak of ar-n-p. due to $t$ he formation of ar-p-n, it can be preliminarily inferred th at HCCP and DDS have polymerized to form a new subs tance.

\subsubsection{XPS characterization of PZD microspheres}
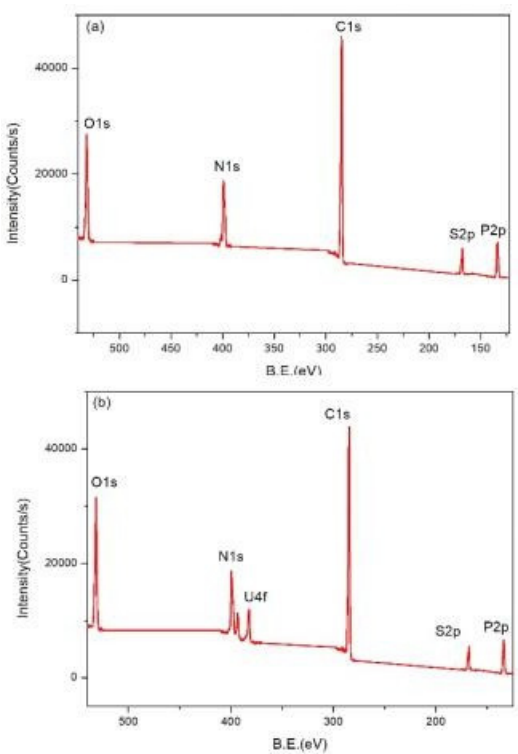

Fig.1XPS spectra of the PZD microspheres before(a) and after (b) adsorption 
In order to determine the composition of the elements in PZD microspheres, XPS was used. The XPS spectrum of PZD microspheres is shown in Fig.1 It can be seen from figure a that the surface of PZD microspheres is compos ed of $\mathrm{C}, \mathrm{N}, \mathrm{O}, \mathrm{P}$ and $\mathrm{S}$ elements, in which $\mathrm{Cl}, \mathrm{N}, \mathrm{O}, \mathrm{P}$ an $\mathrm{d}$ S elements account for $63.93 \%, 11.33 \%, 11.52 \%, 6.94 \%$ and $6.27 \%$ respectively. It can be seen from figure B that the peak of uranium (VI) appears obviously after ads orption, and the proportion of uranium (VI) is $0.33 \%$, wh ich indicates that PZD microspheres have a certain adsor ption effect on uranium (VI) in aqueous solution.

\subsubsection{Bet characterization of PZD microspheres}
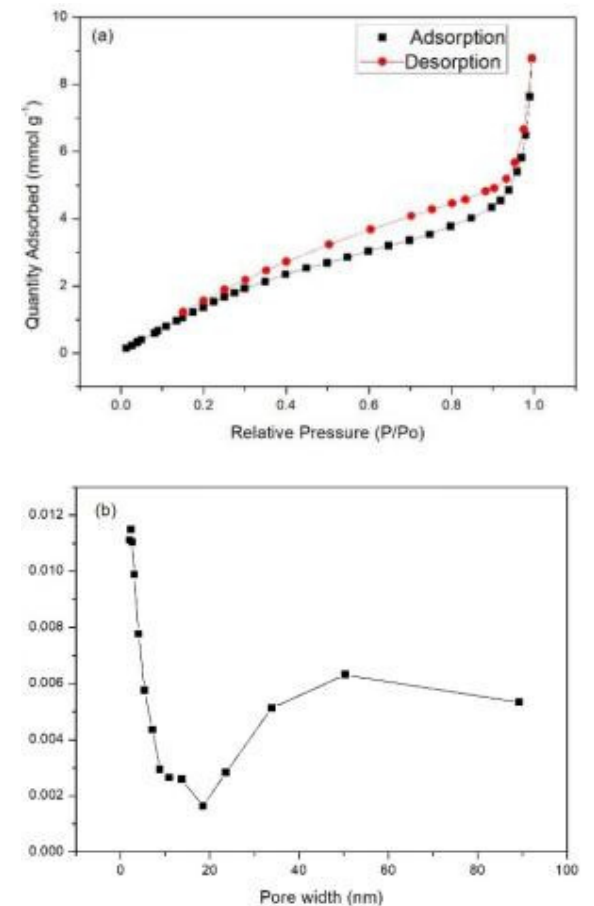

Fig.2 Nitrogen adsorption-desorption isotherm obtained at $77 \mathrm{~K}$ for the PZD ( $b$ ) The pore size distribution curve of the PZD In order to determine the specific surface area and pore $\mathrm{s}$ ize of PZD microspheres, the PZD microspheres were ch aracterized by bet. As shown in Figure 2.4, the BET spec ific surface area of PZD microspheres is $10.42 \mathrm{~m} 2 / \mathrm{g}$, the $\mathrm{t}$ otal pore volume is $0.012 \mathrm{~cm} 3 / \mathrm{g}$, and the pore size is 5.21 $\mathrm{nm}$, which is a mesoporous material. It can be seen that $\mathrm{t}$ he specific surface area of the adsorption material is goo $\mathrm{d}$, which can provide a certain adsorption site for the ads orption of uranium (VI) [7].

\subsubsection{Characterization of PZD microspheres by $S E$ $M-E D S$}

Accurately measure $10 \mathrm{ml}$ of $30 \mathrm{mg}$ - L-1 uranium (VI) solution and adjust the $\mathrm{pH}$ of the solution to $3.5 .5 \mathrm{mg}, 10 . \mathrm{It}$ can be seen from figure 6 that the material presents a $r$ egular and uniform ball shape. However, after adsorption, the material becomes irregular and even flat. It can be se en from Fig.7 that there is one more uranium element on the PZD microspheres after adsorption than before, whic $\mathrm{h}$ further indicates that the PZD has successfully adsorbe d uranium (VI) on its surface.

\subsection{Effect of $\mathrm{pH}$ value on adsorption of uranium (VI) by PZD microspheres}

When the $\mathrm{pH}$ is less than 3.5 , with the increase of $\mathrm{pH}$ val ue, the adsorption capacity of PZD microspheres for ura nium (VI) increases gradually. This may be due to the ex istence of a large number of positively charged $\mathrm{H}+$ in th $\mathrm{e}$ uranium solution under strong acid conditions, and thes e positively charged hydrogen ions may be easier to com bine with the adsorption sites in PZD microspheres, resul ting in protonation of PZD microspheres, The protonated microspheres will repel the positively charged uranium (VI) ions, which is not conducive to the adsorption of ur anium (VI) in solution by PZD microspheres [8]. Howev er, when the $\mathrm{pH}$ of the solution is higher than 4 , the adso rption capacity of PZD microspheres for uranium present $\mathrm{s}$ a downward trend. This is because when the $\mathrm{pH}$ value $\mathrm{e}$ xceeds 4, uranium (VI) is easy to hydrolyze, even to for $\mathrm{m}$ negatively charged (UO2) $3(\mathrm{OH}) 7$-, and the appeara nce of this ion will produce repulsive force with the PZD surface, resulting in the decrease of the adsorption stren gth of the adsorbent. In conclusion, when the $\mathrm{pH}$ value of the solution is 3.5 , the adsorption behavior of PZD micr ospheres is the best, and the optimal adsorption capacity is about $12.79 \mathrm{mg} \cdot \mathrm{g}-1$.

\subsection{Effect of solid-liquid ratio on adsorption of urani um (VI) by PZD microspheres}

In order to study the effect of solid-liquid ratio on the ad sorption of uranium (VI) by PZD microspheres, experiments were carried out under the conditions of initial conc entration of uranium (VI) $30 \mathrm{mg}$ - L-1, shaking adsorpti on for $6 \mathrm{~h}, \mathrm{pH}=3.5$, volume of uranium (VI) solution $10 \mathrm{ml}$ and adsorbent dosage $(5-30 \mathrm{mg})$. It can be seen that with the increase of solid-liquid ratio (M / V), the remov al rate of uranium (VI) by PZD microspheres gradually i ncreases, and when the solid-liquid ratio is greater than $2.0 \mathrm{~g} \cdot \mathrm{L}-1$, it gradually tends to be flat, and the removal rate is $86 \%$. This may be due to the existence of a certain "shielding effect [9]" on the surface of the adsorbent aft er reaching a certain amount of adsorption, which has a $\mathrm{c}$ ertain repulsion to the remaining uranium (VI) ions. At $\mathrm{t}$ his time, due to the decrease of the concentration of uran ium (VI) ions, there is not enough driving force to offset the repulsion force. Therefore, it can be inferred that the best adsorption condition is when the solid-liquid ratio is $2.0 \mathrm{~g} \cdot \mathrm{L}-1$.

\subsection{Effect of initial concentration of uranium (VI) on adsorption of uranium (VI)}

When the initial concentration of uranium (VI) ion is in $\mathrm{t}$ he range of $10-30 \mathrm{mg} \cdot \mathrm{L}-1$, the adsorption capacity of PZD microspheres for uranium (VI) increases with the in crease of uranium (VI) ion concentration. When the initi al concentration of uranium (VI) ion in the solution is gr eater than $30 \mathrm{mg}$ - L-1, the increase of adsorption capa city gradually slows down. It may be that when the conc entration of uranium (VI) ion is high, the number of effe 
ctive collisions between uranium (VI) ion and adsorbent is increased, and the driving force of mass transfer in soli $\mathrm{d}$-liquid phase is improved, so more uranium (VI) ions ar e combined with PZD adsorbent. When the initial conce ntration of $\mathrm{U}(\mathrm{VI})$ in the solution is in the range of $10 \sim 5$ $0 \mathrm{mg} \cdot \mathrm{L}-1$, the removal rate of $\mathrm{U}$ (VI) by PZD microsp heres decreases slowly. It may be that at a higher concen tration of uranium (VI) ion, after uranium (VI) ion reach es a certain concentration, due to the increased competiti on of uranium (VI) ion in the adsorption sites, the adsorp tion sites on the adsorbent that can combine with metal $i$ ons reach saturation [10].

\section{Conclusion}

In this experiment, PZD microspheres, a new adsorbent, were synthesized by precipitation polymerization. The $\mathrm{P}$ ZD microspheres were used to adsorb uranium (VI) in w astewater. The influence of $\mathrm{pH}$ value, solid-liquid ratio, $\mathrm{i}$ nitial solution concentration on adsorption of uranium (VI) by PZD microspheres was studied by single factor method. The results show that PZD microspheres have c ertain adsorption capacity for uranium (VI) in aqueous s olution. The removal rate was over $85 \%$, and the adsorpt ion capacity was close to $12.19 \mathrm{mg} \cdot \mathrm{g}-1$. The best conditi ons for adsorption of uranium (VI) in the waste liquid by PZD microspheres are: $\mathrm{pH}=3.5$, adsorption time is $6 \mathrm{~h}$, solidliquid ratio is $2.0 \mathrm{~g} \cdot \mathrm{L}-1$, and initial concentration o f uranium (VI) is $30 \mathrm{mg} \cdot \mathrm{L}-1$.

\section{Acknowledgment}

Thank you for the financial support of the innovation trai ning program of Nanhua University, project number: 200 $\mathrm{xcx} 158$

\section{References}

1. Bhalara P D, Punetha D, Balasubramanian K. A revi ew of potential remediation techniques for uranium

2. (VI) ion retrieval from contaminated aqueous enviro nment [J]. Journal of Environmental Chemical Engi neering, 2014, 2(3): 1621-1634.

3. Hu e Ming, Shao Er Yan, Zhao Jing et al. Research progress of uranium containing wastewater treatmen $\mathrm{t}$ technology [J]. Hunan Journal of Ecological Scienc es, 2016, 3 (1): 42-48

4. Khamirchi R, Hosseini-Bandegharaei A, Alahabadi A, et al. Adsorption property of Br-PADAP-impregn ated multiwall carbon nanotubes towards uranium a nd its performance in the selective separation and de termination of uranium in different environmental sa mples [J]. Ecotoxicology and Environment Safety, 2 017, 150:136-143.

5. Yin L, Song S, Wang X, et al. Rationally designed c ore-shell and yolk-shell magnetic titanate nanosheet $\mathrm{s}$ for efficient $\mathrm{U}(\mathrm{VI})$ adsorption performance[J]. Env ironmental Pollution, 2018, 238:725-738.
6. Zarrougui R, Mdimagh R, Raouafi N. Highly efficie nt extraction and selective separation of uranium (VI) from transition metals using new class of undiluted ionic liquids based on H-phosphonate anions [J]. Jou rnal of Hazardous Materials, 2017, 342:464.

7. Tan Juan. Adsorption properties of poly (cyclotripho sphazene-co-4,4 '- dihydroxydiphenylsulfone) for th orium (IV) and uranium (VI) [D]. 2018

8. Lu Z, Sun Y, Song L, et al. Dihydroxy bezladely der ivatives functionalized mesoporous silica SBA-15 fo $r$ the sorption of U(VI) [J]. Journal of Radioanalytic al \&amp; Nuclear Chemistry, 2016, 310(1): 1-13.

9. Huynh J, Palacio R, Safizadeh F, et al. Adsorption of Uranium over NH2-Functionalized Ordered Silica in Aqueous Solutions [J]. Acs Appl Mater Interfaces, 2018,22:35-38.

10. GIRI, A. K, PATEL, et al. Artificial neural network (ANN) approach for modelling of arsenic (III) bioso rption from aqueous solution by living cells of Bacil lus cereus biomass [J]. Chemical Engineering Journ al, 2011, 178(24): 15-25.

11. Fu J, Chen Z, Wu X, et al. Hollow poly(cyclotriphos phazene-co-phloroglucinol) microspheres: An effect ive and selective adsorbent for the removal of cation ic dyes from aqueous solution [J]. Chemical Enginee ring Journal, 2015, 281:42-52. 